\title{
BMJ Open Is the HAS-BLED score useful in predicting post-extraction bleeding in patients taking warfarin? A retrospective cohort study
}

\author{
Toshiyuki Kataoka, ${ }^{1}$ Keika Hoshi, ${ }^{2}$ Tomohiro Ando ${ }^{1}$
}

To cite: Kataoka T, Hoshi K, Ando T. Is the HAS-BLED score useful in predicting post-extraction bleeding in patients taking warfarin? A retrospective cohort study. BMJ Open 2016;6:e010471. doi:10.1136/bmjopen-2015010471

- Prepublication history for this paper is available online. To view these files please visit the journal online (http://dx.doi.org/10.1136/ bmjopen-2015-010471).

Received 6 November 2015 Revised 23 January 2016 Accepted 25 January 2016

CrossMark

\footnotetext{
${ }^{1}$ Department of Oral and Maxillofacial Surgery, Tokyo Women's Medical University, Tokyo, Japan

${ }^{2}$ Department of Hygiene, School of Medicine, Kitasato University, Kanagawwa, Japan
}

Correspondence to Dr Toshiyuki Kataoka; kataoka@oms.twmu.ac.jp

\section{ABSTRACT}

Objective: Unexpected post-extraction bleeding is often experienced in clinical practice. Therefore, determining the risk of post-extraction bleeding in patients receiving anticoagulant therapy prior to surgery is beneficial. This study aimed to verify whether the HAS-BLED score was useful in predicting post-extraction bleeding in patients taking warfarin.

Design: Retrospective cohort study.

Setting: Department of Oral and Maxillofacial Surgery, Tokyo Women's Medical University.

Participants: Participants included 258 sequential cases (462 teeth) who had undergone tooth extraction between 1 January 2010 and 31 December 2012 while continuing warfarin therapy.

Main outcome measure: Post-extraction risk factors for bleeding. The following data were collected as the predicting variables for multivariate logistic analysis: the HAS-BLED score, extraction site, tooth type, stability of teeth, extraction procedure, prothrombin time-international normalised ratio value, platelet count and the use of concomitant antiplatelet agents.

Results: Post-extraction bleeding was noted in 21 $(8.1 \%)$ of the 258 cases. Haemostasis was achieved with localised haemostatic procedures in all the cases of post-extraction bleeding. The HAS-BLED score was found to be insufficient in predicting post-extraction bleeding (area under the curve $=0.548, p=0.867$, multivariate analysis). The risk of post-extraction bleeding was approximately three times greater in patients taking concomitant oral antiplatelet agents (risk ratio $=2.881, p=0.035$, multivariate analysis). Conclusions: The HAS-BLED score alone could not predict post-extraction bleeding. The concomitant use of oral antiplatelet agents was a risk factor for postextraction bleeding. No episodes of post-extraction bleeding required more than local measures for haemostasis. However, because this was a retrospective study conducted at a single institution, large-scale prospective cohort studies, which include cases of outpatient tooth extraction, will be necessary in the future.

\section{INTRODUCTION}

Patients on anticoagulant therapy who are scheduled to undergo tooth extraction are

\section{Strengths and limitations of this study}

- This is the first study to investigate the usefulness of the HAS-BLED score for predicting the risk of post-extraction bleeding. We investigated all cases of tooth extraction, including wisdom teeth and impacted tooth extractions.

- No previous reports have investigated the effects of each individual tooth extracted, the extraction procedure and the effects of concomitant antiplatelet agents on post-extraction bleeding using statistical analyses, and, therefore, no high level of evidence for these correlations has so far existed.

- As this study was a retrospective cohort study conducted at a single institution, large-scale prospective cohort studies, including outpatients, are needed in the future.

typically advised to continue anticoagulant therapy. ${ }^{1-4}$ Unexpected post-extraction bleeding is often experienced in clinical practice; however, the development of thromboembolism after tooth extraction because of the discontinuation or reduction of anticoagulant therapy has been reported. ${ }^{5}{ }^{6}$ Although fatal adverse events must be prevented, there is the additional risk of bleeding because of invasive treatment in these patients, and sufficient measures must be taken to prevent and limit excessive post-extraction bleeding. In the past, a number of studies have investigated tooth extraction with continued anticoagulant therapy and have reported that the frequency of post-extraction bleeding was in the range $0-26 \% .^{7-18}$ Blinder et $a \hat{P}^{9}$ and Evans et $a l^{10}$ reported that there were no differences in the incidence of post-extraction bleeding between a group of patients who had discontinued anticoagulant therapy and a group of those who had continued anticoagulant therapy. Even if the uniform consensus were to be performing tooth extraction with continued anticoagulant 
therapy, the risk of post-extraction bleeding remains. Morimoto et $a l^{19}$ suggested that post-extraction bleeding was strongly affected by local inflammatory conditions. However, there are few reports on the systemic factors contributing to post-extraction bleeding. Recently, the HAS-BLED score ${ }^{20-22}$ has been used as an index for evaluating the risk of bleeding complications in patients taking anticoagulant therapy. The HAS-BLED score evaluates nine risk factors for bleeding. The European Society of Cardiology guidelines ${ }^{23}$ state that patients who score three points or higher are at a greater risk of bleeding complications. However, to date, no reports have examined the relationship between post-extraction bleeding and the HAS-BLED score.

Preoperative identification of patients at high risk of post-extraction bleeding could facilitate appropriate preparations prior to performing tooth extraction. Therefore, we examined whether the HAS-BLED score was useful in predicting post-extraction bleeding in patients on warfarin therapy.

\section{MATERIALS AND METHODS}

Study design

This was a retrospective cohort study.

\section{Study population and eligibility criteria}

The study subjects were included from 258 sequential inpatient cases at the Department of Oral and Maxillofacial Surgery, Tokyo Women's Medical University, who underwent tooth extraction between 1 January 2010 and 31 December 2012, while receiving a maintenance dose of warfarin. As a general rule, we performed inpatient tooth extraction in patients taking warfarin. Concomitant antiplatelet agents were continued at the maintenance dose. The exclusion criteria were as follows: (1) patients younger than 20 years of age at the time of hospital admission; (2) the presence of comorbid blood diseases and (3) a prothrombin timeinternational normalised ratio (PT-INR) level of $\geq 3.1$, as indicated by blood tests performed on the day of the tooth extraction. Patients underwent follow-up examinations for 1 month after discharge. The doctors' and nurses' records obtained from the medical examination records were registered in a database along with the results of the clinical tests. When the same patient was hospitalised and underwent tooth extraction more than once during the study period, all instances were included in the analysis.

\section{Tooth extraction procedure}

Each patient's primary physician was consulted preoperatively regarding the general medical status and the use of anticoagulants. When acute symptoms, such as periodontal abscesses, apical periodontitis, or pericoronitis, were present around the tooth to be extracted, antibiotics were administered for at least 3 days and antiinflammation procedures, such as incision and drainage, were performed as necessary. During the tooth extraction, ECG, blood pressure, pulse rate and percutaneous oxygen saturation levels were monitored. For local anaesthesia, $1.8-3.6 \mathrm{~mL}$ of $2 \%$ lidocaine containing 1/80 000 units of epinephrine was administered. Tooth extraction was performed with minimal invasion. When multiple teeth were indicated for extraction and comprised within $1 / 3$ of the jaw area, all the teeth were extracted in one procedure. When the teeth comprised over $1 / 3$ of the total jaw area, multiple teeth were extracted in one procedure if the procedure was expected to take $<30 \mathrm{~min}$, while at the same time considering the age of the patient and any comorbid diseases. After extraction, curettage of inflammatory granulation tissue around the wound border was performed, a haemostatic gelatine sponge was inserted into the socket (Spongel, Astellas Pharma Inc) and suturing was performed to reduce the size of the wound border. The patient was requested to bite down on a piece of absorbent cotton for $20 \mathrm{~min}$ after completion of the tooth extraction, in order to achieve pressure haemostasis. At $30 \mathrm{~min}$ after the tooth extraction, the patient was examined to confirm that the bleeding had stopped. After extraction, patients were instructed to avoid strong or frequent gargling and to rest as much as possible. Post-extraction meals were comprised of rice gruel. In patients with a high risk of developing infective endocarditis, ${ }^{24}$ intravenous antibiotics were administered before surgery and oral antibiotics were administered for 3 days after the tooth extraction. For patients with heart disease on anticoagulant therapy who did not require infectious endocarditis prophylaxis, oral antibiotics were administered for 3 days following tooth extraction. Five doses of analgesics, which comprised loxoprofen sodium or acetaminophen, were prescribed as medication when pain was experienced.

\section{Post-extraction bleeding}

Patients who had bleeding but in whom haemostatic procedures were not deemed necessary were instructed to get adequate rest and refrain from excessive gargling. Regular follow-up examinations were performed. If patients had mild bleeding and oozing, they were requested to bite down for $20 \mathrm{~min}$ on a piece of gauze or absorbent cotton placed on the tooth extraction wound in order to achieve pressure haemostasis. These patients who did not require medical treatment for postextraction bleeding were categorised into the non-post-extraction bleeding group.

Patients who had bleeding on examination after the tooth extraction and who underwent some form of medical haemostatic procedure were categorised into the post-extraction bleeding group. The haemostatic procedures that were performed in accordance with the decision of the examining oral surgeon are described below. In cases of moderate to severe bleeding that were difficult to resolve using primary haemostasis alone, the local dental anaesthetic, epinephrine, which has vasoconstrictive effects, was infiltrated at a dose of 1.0 
$1.8 \mathrm{~mL}$ around the tooth extraction wound. Pressure was then applied to the wound by asking the patient to bite down on a piece of gauze or absorbent cotton. When it was determined that the bleeding could not be sufficiently halted by pressure haemostasis alone, the area was additionally filled with local haemostatic agents or additional suturing of the wound was performed as necessary. For cases of repeated bleeding or prolonged exudative bleeding after haemostatic procedures, a haemostatic splint was fabricated to cover the wound. This was fitted after applying a cavity lining with a periodontal pack or denture-based tissue conditioner.

\section{Bleeding risk factors for tooth extraction}

The details of extracted teeth, surgical procedure, bleeding tendency and the use of concomitant antiplatelet agents were investigated as possible factors affecting post-extraction bleeding. Details regarding the extracted teeth, extraction site (maxilla/mandible), type of teeth (incisor/premolar/molar/wisdom) and stability of teeth were examined. Teeth exhibiting alveolar bone resorption of at least $2 / 3$ of the tooth root length, as determined by preoperative X-rays, or teeth found to have clinical grade III instability, were defined as having poor stability. The surgical procedure was classified into simple extraction and surgical extraction. For surgical extraction, the strategy followed was to make an incision into the gingiva, detach and turn over the mucoperiosteal flap, and extract the tooth after cutting off the alveolar bone or root separation. All other extractions were defined as simple extractions. With respect to the bleeding tendency, the PT-INR value and platelet count were examined.

\section{HAS-BLED score}

The HAS-BLED score was evaluated according to the European Society of Cardiology guidelines ${ }^{23}$ (table 1), and is described below. Patients with a systolic blood pressure of $\geq 160 \mathrm{~mm} \mathrm{Hg}$, which was measured on arrival at the hospital, were categorised as having 'hypertension'. Patients were categorised as having 'abnormal renal or liver function' based on the following conditions: (1) patients receiving haemodialysis or those who had undergone a kidney transplant; (2) patients with a serum creatinine level of $\geq 2.26 \mathrm{mg} / \mathrm{dL}$ in the most recent blood test; (3) patients exhibiting chronic liver disease, such as liver cirrhosis, and bilirubin levels of at least two times the normal upper limit; and (4) patients with at least three times the normal upper limit of either alanine transaminase, aspartate aminotransferase or alkaline phosphatase levels. Patients were categorised as having 'stroke' or 'bleeding' based on the information obtained from the medical interviews on admission to the hospital. 'Labile INRs' were described as unstable/ high INRs or poor time in therapeutic range (eg, $<60 \%)$. Patients who were $\geq 65$ years of age at the time of tooth extraction were categorised as 'elderly'. Patients with long-term administration of antiplatelet agents or
Table 1 HAS-BLED bleeding risk score

\begin{tabular}{l} 
Risk factor \\
\hline H Hypertension \\
A Abnomal renal and \\
liver function (1 point \\
each)
\end{tabular}

Clinical characteristics

Uncontrolled, >160 mm Hg systolic

Presence of chronic dialysis, renal transplantation or serum creatinine $\geqq 200 \mu \mathrm{mol} / \mathrm{L}$ Chronic hepatic disease (eg, cirrhosis), bilirubin $>2 \times$ upper limit of normal

AST/ALT/ALP > $3 \times$ upper limit of normal

S Stroke

B Bleeding

Previous history

Bleeding history or predisposition

L Labile INRs Unstable/high INRs or poor time in therapeutic range (eg, $<60 \%)$

E Elderly

D Drugs or alcohol (1 point each)

$>65$ years

Concomitant antiplatelet agents and NSAIDs Alcohol excess

Criteria from the European Society of Cardiology ${ }^{23}$ were used. ALP, alkaline phosphatase; ALT, alanine aminotransferase; AST, aspartate aminotransferase; NSAIDs, non-steroidal anti-inflammatory drugs.

non-steroidal anti-inflammatory drugs (NSAIDs) or patients with alcohol dependency were categorised into a 'drug and alcohol' group. One point was allocated for each of these categories with a possible full score of nine points.

\section{Selection of representative teeth}

Of the sequential cases in this study, some patients had duplicate tooth extractions at different time periods; however, the age of the patient, PT-INR values and the tooth extraction site were different for each extraction. In cases of extraction of multiple teeth in the same patient, each period was treated as independent data with the representative tooth following the procedure. The most posterior tooth was selected as the representative tooth, and in cases of multiple posterior teeth, the upper tooth or the tooth showing the best stability was selected.

\section{Statistical analyses}

Statistical analysis involved processing the data of the patient with the representative tooth. Univariate and multivariate logistic analyses were applied to analyse the bleeding risk factors for the tooth extraction data with the presence/absence of post-extraction bleeding as the response variable and the bleeding risk factor as the explanatory variable. Two variable values were used to describe the tooth extraction site (maxilla/mandible), four variable values were used to describe the type of teeth (incisor/premolar/molar/wisdom), two variable values were used to describe the stability of teeth 
(good/poor) and two variable values were used to describe the surgical procedure (simple/surgical extraction). For the PT-INR value and platelet count, the actual measured values were analysed as continuous variables, and the HAS-BLED score was used in the analysis as both a continuous and a nominal variable. Concomitant antiplatelet agents were evaluated as two variable values (yes/no). During logistic analysis, we calculated the risk ratio (RR), 95\% CI and $p$ value. The RR was calculated as the ratio of 'maxilla' to 'mandible' for the site, the tooth type within the anterior teeth for the type of teeth, 'good' to 'poor' for the condition of the periodontium and from 'surgical' to 'simple' for the surgical procedure. The RR for the HAS-BLED score was calculated for each level. For concomitant antiplatelet agents, the RR of 'yes' to 'no' was calculated. In the multivariate analysis, RRs were combined to create postextraction bleeding analysis models. For each model, we plotted the receiver operating characteristic (ROC) curve, and calculated the area under the curve (AUC) in addition to the $\mathrm{p}$ value and 95\% CI for the C-statistical model overall. Many screening tools have used a C-statistical value of $\geq 0.70$. We used the C-statistic for comparisons between each model. Model 1 was constructed from the extracted tooth state, surgical procedure and bleeding tendency. Model 2 was constructed from the HAS-BLED score only. Model 3 was constructed by adding the HAS-BLED score to model 1. Model 4 was constructed by adding concomitant antiplatelet agents as an explanatory variable to model 1. Data were analysed with the use of JMP Pro V.11 software (2014 SAS Institute Inc, USA) with a two-tailed $\alpha$ level of 0.05 .

\section{RESULTS}

A total of 462 extracted teeth in 258 patients (males: 157, females: 101) were analysed. Post-extraction bleeding was observed in 21 patients (8.1\%). Haemostasis with a localised haemostatic procedure was performed in all the cases of post-extraction bleeding and no patients died from haemorrhage.

\section{Patient characteristics}

Post-extraction bleeding was noted in 21 patients (males: 14, females: 7 ; mean age: $63.4 \pm 13.2$ years). Table 2 shows the underlying diseases for which anticoagulant therapy was prescribed. The mean warfarin dosage was 3.9 $\pm 1.4 \mathrm{mg}$, and the median (25th centile, 75th centile) PT-INR was $2.1(1.8,2.5)$. The mean platelet count was $16.8 \pm 5.3 \times 10^{4} / \mu \mathrm{L}$. Eleven patients were taking only warfarin, and 10 patients were taking an antiplatelet agent in addition to warfarin. Aspirin was administered as the antiplatelet agent in all cases.

The non-post-extraction bleeding group included 237 patients (males: 143, females: 94; mean age: 66.6 \pm 13.7 years). The underlying diseases for which anticoagulant therapy was prescribed are shown in table 2 .
The mean warfarin dosage was $3.2 \pm 1.3 \mathrm{mg}$. The median (25th centile, 75th centile) PT-INR was $2.0(1.8,2.3)$. The mean platelet count was $18.2 \pm 5.8 \times 10^{4} / \mu \mathrm{L}$. A total of 174 patients were taking only warfarin, and 63 patients were taking warfarin and an antiplatelet agent. Table 2 shows a breakdown of the antiplatelet agents. Seven patients who were taking two types of antiplatelet agents were all categorised into the non-post-extraction bleeding group. Between the two groups, a statistically significant difference was noted for the warfarin dosage; however, no significant difference was noted for PT-INR. In addition, no significant differences were noted for age, sex, platelet count and concomitant antiplatelet agent use.

\section{Details of the extracted tooth}

In the post-extraction bleeding group, the maxilla was the tooth extraction site in 14 cases and the mandible was the site in 7 cases. For the non-post-extraction bleeding group, the maxilla was the tooth extraction site in 122 cases and the mandible was the site in 115 cases. No significant differences were noted between the two groups ( $p=0.254$, Fisher's exact test; table 3$)$.

\section{Results for tooth type}

The numbers of incisor, premolar, molar and wisdom teeth were 1, 2, 9 and 9, respectively, for the postextraction bleeding group, and 36, 65, 89 and 47, respectively, for the non-post-extraction bleeding group. A statistically significant difference was noted between the two groups ( $\mathrm{p}=0.039$, Fisher's exact test; table 3$)$.

In the post-extraction bleeding group, 17 cases showed good stability of teeth, whereas 4 cases showed poor stability. In the non-post-extraction bleeding group, 158 cases showed good stability, whereas 79 cases showed poor stability. No statistically significant difference was noted between the two groups $(p=0.227$, Fisher's exact test; table 3).

\section{Extraction procedure}

In the post-extraction bleeding group, the selected extraction procedure was simple extraction in 17 cases and surgical extraction in 4 cases. In the non-post-extraction bleeding group, the selected extraction procedure was simple extraction in 165 cases and surgical extraction in 72 cases. No significant differences were noted between the two groups $(\mathrm{p}=0.328$, Fisher's exact test; table 3).

\section{Number of teeth extracted per operation}

The number of teeth extracted per operation was 1.7 \pm 0.6 in the post-extraction bleeding group and $1.8 \pm 1.1$ in the non-post-extraction bleeding group. There were no cases of multiple extractions of four or more teeth in the post-extraction bleeding group. No significant difference was noted between the two groups with respect to the number of teeth extracted per operation $(p=0.576$, Student t test; table 3). 
Table 2 Patient characteristics

\begin{tabular}{|c|c|c|c|c|c|}
\hline & $\begin{array}{l}\text { Post-extraction } \\
\text { bleeding group } \\
\mathrm{N}=21 \\
\text { Number of patients }\end{array}$ & $\begin{array}{l}\text { Non post-extraction } \\
\text { bleeding group } \\
\mathrm{N}=237 \\
\text { Number of patients }\end{array}$ & p Value & $\begin{array}{l}\text { Significant } \\
\text { difference }\end{array}$ & $\chi^{2}$ value \\
\hline Age $($ mean $\pm S D)$ & $63.4 \pm 13.2$ & $66.6 \pm 13.7$ & $0.294 \dagger$ & & \\
\hline Gender (male/female) & $14 / 7$ & $143 / 94$ & $0.646 \ddagger$ & & 0.32 \\
\hline \multicolumn{6}{|l|}{ Primary disease } \\
\hline Post heart valve & 17 & 120 & & & \\
\hline \multicolumn{6}{|l|}{ Prosthesis implantation } \\
\hline Atrial fibrillation & 2 & 76 & & & \\
\hline Cerebral infarction & 2 & 13 & & & \\
\hline Dilated cardiomyopathy & 1 & 9 & & & \\
\hline Myocardial infarction & 0 & 23 & & & \\
\hline Deep vein thrombosis & 0 & 11 & & & \\
\hline Arteriosclerosis obliterans & 0 & 3 & & & \\
\hline Intracardiac thrombus & 0 & 2 & & & \\
\hline \multicolumn{6}{|l|}{ Anticoagulation } \\
\hline $\begin{array}{l}\text { Warfarin dose }(\mathrm{mg}) \text { (mean } \\
\pm \mathrm{SD} \text { ) }\end{array}$ & $3.9 \pm 1.4$ & $3.2 \pm 1.3$ & $0.024 \dagger$ & * & \\
\hline $\begin{array}{l}\text { PT-INR value (mean ( } 25 \% \\
\text { centile, } 75 \% \text { centile)) }\end{array}$ & $2.1(1.8,2.5)$ & $2.0(1.8,2.3)$ & $0.330 \S$ & & \\
\hline Platelet count $\left(\times 10^{4} / \mu \mathrm{L}\right)$ & $16.8 \pm 5.3$ & $18.2 \pm 5.8$ & $0.298 \dagger$ & & \\
\hline \multicolumn{6}{|c|}{ Concomitant antiplatelet agents } \\
\hline Yes & 10 & 63 & $0.073 \ddagger$ & & 4.21 \\
\hline Aspirin & 10 & 52 & & & \\
\hline Ticlopidine & 0 & 8 & & & \\
\hline Ethyl icosapentate & 0 & 6 & & & \\
\hline Cilostazol & 0 & 2 & & & \\
\hline Limaprost & 0 & 1 & & & \\
\hline Dipyridamole & 0 & 1 & & & \\
\hline \multicolumn{6}{|c|}{$\begin{array}{l}\text { Multiple factors possible for underlying disease; all seven patients using two types of antiplatelet agents were included in the } \\
\text { non-post-extraction bleeding group. } \\
\text { * } p<0.05 \text {. } \\
\text { tStudent } t \text { test. } \\
\text { tFisher's exact test. } \\
\text { §Mann-Whitney U test. }\end{array}$} \\
\hline
\end{tabular}

\section{HAS-BLED score}

The highest HAS-BLED score obtained was three points. The mean score was $1.3 \pm 0.9$ in the post-extraction bleeding group and $1.2 \pm 0.8$ in the non-post-extraction bleeding group. No statistically significant difference was noted between the two groups $(\mathrm{p}=0.467$, Student $\mathrm{t}$ test; table 4).

\section{Statistical examination}

Univariate analysis demonstrated statistically significant differences between the wisdom teeth and incisors $(\mathrm{RR}=8.894, \mathrm{p}=0.027)$ and between concomitant antiplatelet agents $($ yes $/ \mathrm{no}) \quad(\mathrm{RR}=2.511, \mathrm{p}=0.500) . \mathrm{RR}$ was $\leq 1$ for the surgical procedure and platelet count. No statistically significant difference was noted between a HAS-BLED score of $\geq 3$ and a HAS-BLED score of $\leq 2$ $(\mathrm{RR}=1.362, \mathrm{p}=0.7033$; table 5$)$.

No statistically significant differences were noted within multivariate analysis for any of the parameters in model 1,2 or 3 . In model 4, a statistically significant difference was noted for antiplatelet agents (yes) in the non-post-extraction bleeding group $(\mathrm{RR}=2.881, \mathrm{p}=0.035$; table 6 ). The AUCs for models 1,3 and 4 were 0.7 , with a statistically significant difference noted only in model 4 . The AUC for model 2 was the lowest at 0.5 , and a statistically significant difference was noted between models 2 and $3(\mathrm{p}=0.004$; table 7$)$.

\section{DISCUSSION}

Our investigation of 258 tooth extraction patients indicated that post-extraction bleeding occurred in 21 patients (8\%), in 39 of the total 462 extracted teeth $(8 \%)$. In all the cases of post-extraction bleeding, haemostasis was possible with localised haemostatic procedures. The HAS-BLED score alone could not predict post-extraction bleeding. On considering all the risk factors for post-extraction bleeding statistically, concomitant antiplatelet agent use was a risk factor. It has been reported that the incidence of bleeding in an anticoagulation group was the same (approximately $6-7 \%$ ) as in 
Table 3 Details of extracted teeth

\begin{tabular}{|c|c|c|c|c|c|}
\hline & $\begin{array}{l}\text { Post-extraction } \\
\text { bleeding group } \\
\mathrm{N}=21 \\
\text { Number of patients } \\
\text { or mean } \pm \mathrm{SD}\end{array}$ & $\begin{array}{l}\text { Non-post-extraction } \\
\text { bleeding group } \\
\mathrm{N}=237 \\
\text { Number of patients } \\
\text { or mean } \pm \mathrm{SD} \\
\end{array}$ & p Value & $\begin{array}{l}\text { Significant } \\
\text { difference }\end{array}$ & $\chi^{2}$ value \\
\hline \multicolumn{6}{|l|}{ Extraction site } \\
\hline Maxilla & 14 & 122 & $0.254 \dagger$ & & 1.79 \\
\hline Mandible & 7 & 115 & & & \\
\hline \multicolumn{6}{|l|}{ Tooth type } \\
\hline Incisor & 1 & 36 & $0.039 \dagger$ & * & 8.70 \\
\hline Premolar & 2 & 65 & & & \\
\hline Molar & 9 & 89 & & & \\
\hline Wisdom & 9 & 47 & & & \\
\hline \multicolumn{6}{|l|}{ Stability of teeth } \\
\hline Good & 17 & 158 & $0.227 \dagger$ & & 1.80 \\
\hline Poor & 4 & 79 & & & \\
\hline \multicolumn{6}{|l|}{ Extraction procedure } \\
\hline Simple & 17 & 165 & $0.328 \dagger$ & & 1.19 \\
\hline Surgical & 4 & 72 & & & \\
\hline $\begin{array}{l}\text { Number of teeth extracted in } \\
\text { operation }\end{array}$ & $1.7 \pm 0.6$ & $1.8 \pm 1.1$ & $0.576 \ddagger$ & & \\
\hline One tooth & 8 & 125 & $0.188 \dagger$ & & 9.12 \\
\hline Two teeth & 12 & 65 & & & \\
\hline Three teeth & 1 & 24 & & & \\
\hline Four teeth & 0 & 18 & & & \\
\hline Five teeth & 0 & 3 & & & \\
\hline Six teeth & 0 & 1 & & & \\
\hline Seven teeth & 0 & 1 & & & \\
\hline
\end{tabular}

an anticoagulation withdrawal group. ${ }^{25}$ The postextraction bleeding in this study was in accordance with this report.

Many cases of tooth extraction that have been performed while continuing anticoagulant therapy have been reported. ${ }^{1}$ 7-18 $26{ }^{27}$ However, in the clinical setting, it is not uncommon to encounter post-extraction bleeding during tooth extraction in cases with an optimal INR value range. In a multicentre large-scale study, Iwabuchi et $a l^{28}$ reported that the risk factors for post-extraction bleeding in patients taking warfarin were age, PT-INR and inflammation at the extraction site. To date, although many reports did not include cases of surgical extraction, such as the extraction of wisdom teeth and impacted teeth, these types of surgical extraction are often performed in the clinical setting. Therefore, this study targeted cases that were managed in the optimal treatment range and concurrently investigated all cases of tooth extraction, including the extraction of wisdom teeth, impacted teeth and multiple teeth.

Various methods of haemostasis have been reported for cases of tooth extraction performed while continuing warfarin therapy. These include pressure haemostasis alone, wound suturing and the application of local haemostatic agents. ${ }^{29-31}$ To implement haemostasis, we placed a haemostatic gelatine sponge in the extraction socket and routinely conducted pressure haemostasis using absorbent cotton with suturing of the wound. Patients were examined $30 \mathrm{~min}$ after tooth extraction to confirm whether the bleeding had stopped. Haemostasis was determined to have been sufficient in all cases. As all patients underwent tooth extraction on an inpatient basis, the patient could rapidly be examined by an oral surgeon or a nurse and could receive early diagnosis and appropriate treatment if post-extraction bleeding was suspected. However, although the patients were examined, many did not require haemostatic treatment. Of the patients who exhibited post-extraction bleeding, no systemic haemostatic treatment, such as blood transfusion, was required in any of the cases.

The HAS-BLED score is used in cardiology to evaluate the risk of haemorrhage in patients with adequate anticoagulation. It would be highly significant if the HAS-BLED score could be used to predict the risk of post-extraction bleeding, and, therefore, we evaluated its use in this study. We found that the highest HAS-BLED score was three points. A score of 1 point was the most commonly achieved score among the 137 patients $(53 \%)$. The commonest risk factor was age (174 
Table 4 HAS-BLED score

\begin{tabular}{|c|c|c|c|c|c|}
\hline & $\begin{array}{l}\text { Post-extraction } \\
\text { bleeding group } \\
\mathrm{N}=21 \\
\text { Mean } \pm \mathrm{SD} \text { or } \\
\text { number } \\
\text { of patients }\end{array}$ & $\begin{array}{l}\text { Non-post-extraction } \\
\text { bleeding group } \\
\mathrm{N}=237 \\
\text { Mean } \pm \mathrm{SD} \\
\text { or number of } \\
\text { patients }\end{array}$ & $\begin{array}{l}p \\
\text { Value }\end{array}$ & $\begin{array}{l}\text { Significant } \\
\text { difference }\end{array}$ & $\begin{array}{l}\chi^{2} \\
\text { value }\end{array}$ \\
\hline $\begin{array}{l}\text { HAS-BLED } \\
\text { score }\end{array}$ & $1.3 \pm 0.9$ & $1.2 \pm 0.8$ & $0.467^{\star}$ & & \\
\hline 0 & 3 & 41 & $0.804 \dagger$ & & 0.75 \\
\hline 1 & 10 & 127 & & & \\
\hline 2 & 6 & 52 & & & \\
\hline 3 & 2 & 17 & & & \\
\hline 4 & 0 & 0 & & & \\
\hline 5 & 0 & 0 & & & \\
\hline 6 & 0 & 0 & & & \\
\hline 7 & 0 & 0 & & & \\
\hline 8 & 0 & 0 & & & \\
\hline 9 & 0 & 0 & & & \\
\hline \multicolumn{6}{|l|}{ Risk factor } \\
\hline $\mathrm{H}$ & 1 & 3 & & & \\
\hline A & 1 & 11 & & & \\
\hline $\mathrm{s}$ & 2 & 38 & & & \\
\hline B & 0 & 5 & & & \\
\hline L & 0 & 0 & & & \\
\hline$E$ & 13 & 161 & & & \\
\hline D & 11 & 63 & & & \\
\hline
\end{tabular}

patients; $67 \%$ ). No significant difference was noted for the mean HAS-BLED score between the post-extraction bleeding and non-post-extraction bleeding groups. The European Society of Cardiology has proposed that a HAS-BLED score $\geq 3$ indicates a high risk of haemorrhagic complications. In the cases of post-extraction bleeding, we compared patients with a HAS-BLED score of three or higher with those having a score of 2 or lower but did not detect any statistically significant difference (univariate analysis; $\mathrm{RR}=1.362, \quad \mathrm{p}=0.703$ ). Multivariate analysis indicated that there was little risk associated with the score increasing by one (table 6 ). The AUC for the HAS-BLED score alone (model 2) was 0.55 , which was the lowest for all of the models that we constructed. In model 3 , to which the details of extracted teeth were added to the HAS-BLED score, AUC was 0.745 , suggesting that this model is useful for predicting post-extraction bleeding. However, a statistically significant difference was noted for model 2 vs 3 $(\mathrm{p}=0.004)$, indicating that the HAS-BLED score alone was insufficient for predicting post-extraction bleeding.

As bleeding risk factors for tooth extraction, investigation of the conditions of the individual teeth extracted indicated that the post-extraction bleeding risk was five to six times higher for wisdom teeth compared with that for anterior teeth. The extraction site and stability had little effect. Although no differences were observed for the number of teeth extracted in one treatment, there were no cases of multiple extractions of four or more teeth in the post-extraction bleeding group. Although we predicted that surgical extraction was a risk factor for post-extraction bleeding, the results indicated that surgical extraction hardly had any effect on post-extraction bleeding $(\mathrm{RR}=0.539, \mathrm{p}=0.256)$.

Effects of warfarin can be possibly affected by the interactions between meals and medicine, and by the general state of the patient. Therefore, in this study, to accurately determine the anticoagulation state directly before tooth extraction, all blood tests were performed before breakfast on the tooth extraction day, or the first tooth extraction day if tooth extraction was planned on consecutive days. Although post-extraction bleeding cases were receiving high doses of warfarin, no difference was observed in PT-INR values. There were no cases classified as having labile INRs. Accordingly, the PT-INR value was investigated using actual measured values as the continuous variable. There were no statistically significant differences noted for PT-INR values by either univariate or multivariate analyses $(p \geq 0.1)$, suggesting that the PT-INR value had little effect on postextraction bleeding in patients on anticoagulant therapy while being managed within the optimal treatment range.

There has been no fixed consensus regarding the concomitant use of warfarin and antiplatelet agents because some reports have indicated that these increase the risk 
Table 5 Univariate analysis of bleeding risk factor in teeth extraction

\begin{tabular}{|c|c|c|c|c|c|}
\hline & \multirow[b]{2}{*}{$\begin{array}{l}\text { Risk } \\
\text { ratio }\end{array}$} & \multicolumn{2}{|l|}{$95 \% \mathrm{Cl}$} & \multirow[b]{2}{*}{$\begin{array}{l}\mathbf{p} \\
\text { Value }\end{array}$} & \multirow[b]{2}{*}{$\begin{array}{l}\text { Significant } \\
\text { difference }\end{array}$} \\
\hline & & Lower & Upper & & \\
\hline \multicolumn{6}{|l|}{ Extraction site } \\
\hline Maxilla/mandible & 1.885 & 0.756 & 5.128 & 0.177 & \\
\hline \multicolumn{6}{|l|}{ Tooth type } \\
\hline Premolar/incisor & 1.108 & 0.103 & 24.300 & 0.934 & \\
\hline Molar/incisor & 3.640 & 0.649 & 68.346 & 0.160 & \\
\hline Wisdom/incisor & 6.894 & 1.213 & 130.039 & 0.027 & * \\
\hline \multicolumn{6}{|l|}{ Stability of teeth } \\
\hline Good/poor & 2.125 & 0.756 & 7.572 & 0.161 & \\
\hline \multicolumn{6}{|l|}{ Extraction procedure } \\
\hline Surgical/simple & 0.539 & 0.151 & 1.518 & 0.256 & \\
\hline PT-INR value & 1.782 & 0.597 & 5.387 & 0.300 & \\
\hline Platelet count $\left(\times 10^{4} / \mu \mathrm{L}\right)$ & 0.959 & 0.887 & 1.037 & 0.296 & \\
\hline \multicolumn{6}{|l|}{ HAS-BLED score } \\
\hline $1 / 0$ & 1.076 & 0.312 & 4.968 & 0.914 & \\
\hline $2 / 0$ & 1.577 & 0.391 & 7.825 & 0.529 & \\
\hline $3 / 0$ & 1.608 & 0.199 & 10.551 & 0.626 & \\
\hline $2 / 1$ & 1.465 & 0.477 & 4.157 & 0.487 & \\
\hline $3 / 1$ & 1.494 & 0.218 & 6.305 & 0.636 & \\
\hline $3 / 2$ & 1.020 & 0.140 & 4.922 & 0.982 & \\
\hline $3 /<2$ & 1.362 & 0.206 & 5.255 & 0.703 & \\
\hline \multicolumn{6}{|c|}{ Concomitant antiplatelet agents use } \\
\hline Yes/no & 2.511 & 1.001 & 6.238 & 0.050 & * \\
\hline
\end{tabular}

of post-extraction bleeding, ${ }^{1} 32$ whereas other reports have suggested that antiplatelet agents have little effect. ${ }^{16}{ }^{19}$ In this study, the incidence of post-extraction bleeding was $13.7 \%$ with concomitant antiplatelet drugs and $5.9 \%$ with warfarin alone. Both the univariate and multivariate analyses indicated that the use of concomitant antiplatelet agents was a significant factor affecting post-extraction bleeding. It has been reported that the concomitant use of two antiplatelet agents significantly increases the frequency of intracranial haemorrhaging. ${ }^{33}$ Furthermore, a prospective observational study of haemorrhagic complications in Japanese cerebral infarction patients ${ }^{34}$ found that compared with patients taking only one antiplatelet agent, those taking two or three antiplatelet agents along with warfarin clearly exhibited higher annual onset rates of intracranial haemorrhaging. These results suggest that concomitant antiplatelet agents are a risk factor for post-extraction bleeding.

The limitations of the present study include the fact that the data were obtained only at a single facility and that outpatients were not included in the participants we investigated. In our facility, there were many patients with cardiovascular diseases, particularly postoperative valve replacement patients at approximately $50 \%$. Furthermore, because patients with a PT-INR of $\geq 3$.1 during the blood testing performed on the day of tooth extraction were excluded, the current study included patients whose anticoagulant therapy was well managed. Therefore, our participants were not exactly representative of generalised cases of tooth extraction patients taking warfarin. Moreover, because this was a retrospective study, we believe that a large-scale, prospective, cohort study, including outpatient tooth extraction cases, needs to be conducted in the future.

Moreover, we could not examine drug interaction effects because our participants included patients who received intravenous antibacterial agents and patients who received oral antibacterial agents. Warfarin has a number of drug interactions. Holbrook et $a l^{35}$ stated that anti-infective agents, lipid-lowering drugs, NSAIDs, including COX-2 selective NSAIDs, selective serotonin reuptake inhibitors, amiodarone, omeprazole, fluorouracil and cimetidine enhance the anticoagulation effects of warfarin. It has been suggested that changing to alternative drugs that have a smaller interactive effect with warfarin should be considered. However, some reports have stated that, in most stable anticoagulant therapy patients, exposure to antibacterial agents did not cause clinical problems; ${ }^{36}$ furthermore, other reports have found that NSAIDs and antibacterial agents often increased warfarin effects only in cases of long-term administration. ${ }^{18}$ We also believe that the short-term or low-dose administration of NSAIDs or antibacterial agents does not cause any prolongation of clinically problematic PT-INR. 
Table 6 Multivariate analysis of post-extraction bleeding

\begin{tabular}{|c|c|c|c|c|c|}
\hline & \multirow[b]{2}{*}{$\begin{array}{l}\text { Risk } \\
\text { ratio }\end{array}$} & \multicolumn{2}{|l|}{$95 \% \mathrm{Cl}$} & \multirow[b]{2}{*}{ p Value } & \multirow[b]{2}{*}{$\begin{array}{l}\text { Significant } \\
\text { difference }\end{array}$} \\
\hline & & Lower & Upper & & \\
\hline \multicolumn{6}{|l|}{ Model 1} \\
\hline \multicolumn{6}{|l|}{ Extraction site } \\
\hline Maxilla/mandible & 1.855 & 0.700 & 5.286 & 0.216 & \\
\hline \multicolumn{6}{|l|}{ Tooth type } \\
\hline Premolar/incisor & 1.118 & 0.102 & 24.727 & 0.928 & \\
\hline Molar/incisor & 3.468 & 0.594 & 65.974 & 0.188 & \\
\hline Wisdom/incisor & 5.228 & 0.850 & 101.628 & 0.078 & \\
\hline \multicolumn{6}{|l|}{ Stability of teeth } \\
\hline Good/poor & 1.790 & 0.551 & 6.994 & 0.344 & \\
\hline \multicolumn{6}{|l|}{ Extraction procedure } \\
\hline Surgical/simple & 0.624 & 0.166 & 1.915 & 0.425 & \\
\hline PT-INR value & 2.078 & 0.681 & 6.606 & 0.204 & \\
\hline Platelet count $\left(\times 10^{4} / \mu \mathrm{L}\right)$ & 0.970 & 0.892 & 1.053 & 0.461 & \\
\hline \multicolumn{6}{|l|}{ HAS-BLED score } \\
\hline $1 / 0$ & - & - & - & - & \\
\hline $2 / 0$ & - & - & - & - & \\
\hline $3 / 0$ & - & - & - & - & \\
\hline $2 / 1$ & - & - & - & - & \\
\hline $3 / 1$ & - & - & - & - & \\
\hline $3 / 2$ & - & - & - & - & \\
\hline \multicolumn{6}{|c|}{ Concomitant antiplatelet agents use } \\
\hline Yes/no & - & - & - & - & \\
\hline \multicolumn{6}{|l|}{ Model 2} \\
\hline \multicolumn{6}{|l|}{ Extraction site } \\
\hline Maxilla/mandible & - & - & - & - & \\
\hline \multicolumn{6}{|l|}{ Tooth type } \\
\hline Premolar/incisor & - & - & - & - & \\
\hline Molar/incisor & - & - & - & - & \\
\hline Wisdom/incisor & - & - & - & - & \\
\hline \multicolumn{6}{|l|}{ Stability of teeth } \\
\hline Good/poor & - & - & - & - & \\
\hline \multicolumn{6}{|l|}{ Extraction procedure } \\
\hline Surgical/simple & - & - & - & - & \\
\hline PT-INR value & - & - & - & - & \\
\hline Platelet count $\left(\times 10^{4} / \mu \mathrm{L}\right)$ & - & - & - & - & \\
\hline \multicolumn{6}{|l|}{ HAS-BLED score } \\
\hline $1 / 0$ & 1.076 & 0.312 & 4.968 & 0.914 & \\
\hline $2 / 0$ & 1.577 & 0.391 & 7.825 & 0.529 & \\
\hline $3 / 0$ & 1.608 & 0.199 & 10.551 & 0.626 & \\
\hline $2 / 1$ & 1.465 & 0.477 & 4.157 & 0.487 & \\
\hline $3 / 1$ & 1.494 & 0.218 & 6.305 & 0.636 & \\
\hline $3 / 2$ & 1.020 & 0.140 & 4.922 & 0.982 & \\
\hline Concomitant antiplatelet ag & & & & & \\
\hline Yes/no & - & - & - & - & \\
\hline Model 3 & & & & & \\
\hline Extraction site & & & & & \\
\hline Maxilla/mandible & 1.914 & 0.716 & 5.494 & 0.198 & \\
\hline Tooth type & & & & & \\
\hline Premolar/incisor & 1.045 & 0.095 & 23.222 & 0.972 & \\
\hline Molar/incisor & 3.388 & 0.579 & 64.544 & 0.199 & \\
\hline Wisdom/incisor & 5.380 & 0.860 & 105.301 & 0.075 & \\
\hline Stability of teeth & & & & & \\
\hline Good/poor & 1.961 & 0.588 & 7.893 & 0.283 & \\
\hline Extraction procedure & & & & & \\
\hline Surgical/simple & 0.674 & 0.177 & 2.125 & 0.515 & \\
\hline PT-INR value & 2.288 & 0.727 & 7.543 & 0.162 & \\
\hline
\end{tabular}


Table 6 Continued

\begin{tabular}{|c|c|c|c|c|c|}
\hline & \multirow[b]{2}{*}{$\begin{array}{l}\text { Risk } \\
\text { ratio }\end{array}$} & \multicolumn{2}{|l|}{$95 \% \mathrm{Cl}$} & \multirow[b]{2}{*}{$\mathrm{p}$ Value } & \multirow[b]{2}{*}{$\begin{array}{l}\text { Significan } \\
\text { difference }\end{array}$} \\
\hline & & Lower & Upper & & \\
\hline Platelet count $\left(\times 10^{4} / \mu \mathrm{L}\right)$ & 0.968 & 0.889 & 1.053 & 0.443 & \\
\hline \multicolumn{6}{|l|}{ HAS-BLED score } \\
\hline $1 / 0$ & 1.197 & 0.325 & 5.777 & 0.798 & \\
\hline $2 / 0$ & 2.271 & 0.515 & 12.242 & 0.284 & \\
\hline $3 / 0$ & 2.338 & 0.269 & 16.989 & 0.410 & \\
\hline $2 / 1$ & 1.897 & 0.580 & 5.871 & 0.279 & \\
\hline $3 / 1$ & 1.954 & 0.266 & 9.403 & 0.463 & \\
\hline $3 / 2$ & 1.030 & 0.130 & 5.605 & 0.975 & \\
\hline \multicolumn{6}{|c|}{ Concomitant antiplatelet agents use } \\
\hline Yes/no & - & - & - & - & \\
\hline \multicolumn{6}{|l|}{ Model 4} \\
\hline \multicolumn{6}{|l|}{ Extraction site } \\
\hline Maxilla/mandible & 1.936 & 0.722 & 5.585 & 0.192 & \\
\hline \multicolumn{6}{|l|}{ Tooth type } \\
\hline Premolar/incisor & 1.159 & 0.104 & 25.901 & 0.906 & \\
\hline Molar/incisor & 3.730 & 0.630 & 71.468 & 0.164 & \\
\hline Wisdom/incisor & 5.113 & 0.804 & 100.719 & 0.804 & \\
\hline \multicolumn{6}{|l|}{ Stability of teeth } \\
\hline \multirow{2}{*}{\multicolumn{6}{|c|}{ Extraction procedure }} \\
\hline & & & & & \\
\hline Surgical/simple & 0.670 & 0.175 & 2.117 & 0.509 & \\
\hline PT-INR value & 2.687 & 0.831 & 9.349 & 0.107 & \\
\hline Platelet count $\left(\times 10^{4} / \mu \mathrm{L}\right)$ & 0.970 & 0.894 & 1.052 & 0.465 & \\
\hline \multicolumn{6}{|l|}{ HAS-BLED score } \\
\hline $1 / 0$ & - & - & - & - & \\
\hline $2 / 0$ & - & - & - & - & \\
\hline $3 / 0$ & - & - & - & - & \\
\hline $2 / 1$ & - & - & - & - & \\
\hline $3 / 1$ & - & - & - & - & \\
\hline $3 / 2$ & - & - & - & - & \\
\hline \multicolumn{6}{|c|}{ Concomitant antiplatelet agents use } \\
\hline Yes/no & 2.881 & 1.079 & 7.740 & 0.035 & * \\
\hline
\end{tabular}

Of the models that we created in this study, model 4 exhibited the highest predictive ability for postextraction bleeding ( $\mathrm{AUC}=0.76, \mathrm{p}=0.0309$ ). However, because there were no significant differences observed between model 1 or 3 versus model 4, we were unable to construct an optimal model for predicting postextraction bleeding. To increase model precision, it may be beneficial to add other factors, such as the surgeon's

Table 7 Comparison of the model

\begin{tabular}{|c|c|c|c|c|c|}
\hline & \multirow[b]{2}{*}{$\begin{array}{l}\text { Area under the } \\
\text { curve }\end{array}$} & \multicolumn{2}{|l|}{$95 \% \mathrm{Cl}$} & \multirow[b]{2}{*}{ p Value } & \multirow[b]{2}{*}{$\begin{array}{l}\text { Significant } \\
\text { difference }\end{array}$} \\
\hline & & Lower & Upper & & \\
\hline Model 1 & 0.738 & 0.630 & 0.824 & 0.083 & \\
\hline Model 2 & 0.548 & 0.425 & 0.666 & 0.867 & \\
\hline Model 3 & 0.745 & 0.632 & 0.832 & 0.148 & \\
\hline Model 4 & 0.763 & 0.650 & 0.847 & 0.031 & * \\
\hline Model 1 vs 3 & & & & 0.727 & \\
\hline Model 1 vs 4 & & & & 0.441 & \\
\hline Model 2 vs 3 & & & & 0.004 & * \\
\hline Model 3 vs 4 & & & & 0.398 & \\
\hline
\end{tabular}


skill (eg, years of experience or time required for one tooth extraction), which were not included in our current investigation. Furthermore, the addition of all extraction data from outpatients to the analysis set is necessary to conduct a multilevel analysis.

Finally, all the patients who had post-extraction bleeding achieved haemostasis with localised haemostatic procedures, and no systemic haemostatic treatment was required. There was no case that warranted extended hospitalisation because of post-extraction bleeding. In agreement with our results, Wahl et al $l^{25}$ stated that bleeding complications requiring more than local haemostatic measures after dental surgery were exceedingly rare. To avoid the onset of fatal thromboembolism, ${ }^{6}$ there is no need to pause or interrupt warfarin therapy for tooth extraction. A special environment for the post-extraction bleeding procedure is not necessary. If the conditions are adequately prepared, we believe that tooth extraction in a patient on warfarin therapy is possible in a private office.

\section{CONCLUSIONS}

1. We investigated post-extraction bleeding for all types of tooth extractions, including impacted teeth, in patients taking warfarin. Minor post-extraction bleeding was observed in $8 \%$ of patients; however, no patients required more than local measures for haemostasis.

2. The HAS-BLED score alone could not predict postextraction bleeding in patients taking warfarin.

3. The use of concomitant antiplatelet agents was a risk factor for post-extraction bleeding. More care must be taken regarding post-extraction bleeding in cases undergoing concomitant use of antiplatelet drugs than in those on warfarin alone.

Acknowledgements The authors would like to extend our gratitude and thanks to the professors at the Department of Oral and Maxillofacial Surgery at Tokyo Women's Medical University, who offered their kind cooperation during this study.

Contributors TA and TK were involved in the planning of the study concept and design. TK wrote the draft of the manuscript. KH and TK were involved in the statistical analysis. TA and TK reviewed and revised the manuscript. TK and $\mathrm{KH}$ take complete responsibility for the integrity of the data and the accuracy of the data analysis. All the authors have read and approved the final manuscript.

Funding This research received no specific grant from any funding agency in the public, commercial or not-for-profit sectors.

Competing interests None declared.

Ethics approval The study was approved by the ethical review board of the Tokyo Women's Medical University (approval number: 3079 ).

Provenance and peer review Not commissioned; externally peer reviewed.

Data sharing statement No additional data are available.

Open Access This is an Open Access article distributed in accordance with the Creative Commons Attribution Non Commercial (CC BY-NC 4.0) license, which permits others to distribute, remix, adapt, build upon this work noncommercially, and license their derivative works on different terms, provided the original work is properly cited and the use is non-commercial. See: http:// creativecommons.org/licenses/by-nc/4.0/

\section{REFERENCES}

1. Scully C, Wolff A. Oral surgery in patients on anticoagulant therapy. Oral Surg Oral Med Oral Pathol Oral Radiol Endod 2002;94:57-64.

2. Perry DJ, Noakes TJ, Helliwell PS. Guideline for the management of patients on oral anticoagulants requiring dental surgery. Br Dent $J$ 2007;203:389-93.

3. Guidelines for Diagnosis and Treatment of Cardiovascular Disease (2008 Joint Working Groups Report). Guidelines for management of anticoagulant and antiplatelet therapy in cardiovascular disease (JCS 2009). http://www.j-circ.or.jp/guideline/pdf/JCS2009_hori_h.pdf (available in December 2015, in Japanese).

4. JCS Joint Working Group. Guidelines for Pharmacotherapy of Atrial Fibrillation (JCS 2013). Circ J 2014;78:1997-2021.

5. Ogiuchi $\mathrm{H}$, Ando $\mathrm{T}$, Tanaka $\mathrm{M}$, et al. Clinical reports on dental extraction from patients undergoing oral anticoagulant therapy. Bull Tokyo Dent Coll 1985;26:205-12.

6. Wahl MJ. Myths of dental surgery in patients on anticoagulant therapy. J Am Dent Assoc 2000;131:77-81.

7. Devani P, Lavery KM, Howell CJ. Dental extractions in patients on warfarin: is alteration of anticoagulant regime necessary? $\mathrm{Br} \mathrm{J}$ Oral Maxillofac Surg 1998;36:107-11.

8. Campbell JH, Alvarado F, Murray RA. Anticoagulation and minor ora surgery: should the anticoagulation regimen be altered? J Oral Maxillofac Surg 2000;58:131-5.

9. Blinder D, Manor $Y$, Martinowitz $U$, et al. Dental extraction in patients maintained on oral anticoagulant therapy: comparison of INR value with occurrence of postoperative bleeding. J Oral Maxillofac Surg 2001;30:518-21.

10. Evans IL, Sayers MS, Gibbons AJ, et al. Can warfarin be continued during dental extraction? Results of randomized controlled trial. $\mathrm{Br} \mathrm{J}$ Oral Maxillofac Surg 2002;40:248-52.

11. Zanon E, Martinelli F, Bacci C, et al. Safety of dental extraction among consecutive patients on oral anticoagulant treatment managed using a specific dental management protocol. Blood Coagul Fibrinolysis 2003;14:27-30.

12. Cannon PD, Dharmar VT. Minor oral surgical procedures in patients on oral anticoagulants—a controlled study. Aust Dent $J$ 2003:48:115-18.

13. Salam S, Yusuf $H$, Milosevic A. Bleeding after dental extractions in patients taking warfarin. Br J Oral Maxillofac Surg 2007;45:463-6.

14. Sacco R, Sacco M, Carpenedo M, et al. Oral surgery in patients on oral anticoagulant therapy: a randomized comparison of different intensity targets. Oral Surg Oral Med Oral Pathol Oral Radiol Endod 2007;104:e18-21.

15. Ferrieri GB, Castiglioni S, Carmagnola D, et al. Oral Surgery in patients on anticoagulant treatment without therapy interruption. J Oral Maxillofac Surg 2007;65:1149-54.

16. Morimoto $\mathrm{Y}$, Niwa H, Minematsu K. Hemostatic management of tooth extractions in patients on oral antithrombotic therapy. J Oral Maxillofac Surg 2008;66:51-7.

17. Fujimori M, Nishimura T, Tani K, et al. Clinical evaluation of postoperative bleeding in patients undergoing antithrombotic therapy. Jpn Stomatol Soc 2010;59:113-22.

18. Shigeta T, Umeda M, Yoshitake M, et al. A clinical study of hemorrhagic complications in patients with antithrombotic therapy who underwent dental extraction without discontinuation of antithrombotic drugs: 282 patients receiving administration of warfarin. Jpn Stomatol Soc 2012;61:1-7.

19. Morimoto $\mathrm{Y}$, Niwa $\mathrm{H}$, Yoneda $\mathrm{T}$, et al. Hemostatic management of tooth extraction in patients undergoing antithrombotic therapy. Jpn Stomatol Soc 2004;53:74-80.

20. Hughes M, Lip GY; Guideline Development Group for the NICE national clinical guideline for management of atrial fibrillation in primary and secondary care. Risk factors for anticoagulation-related bleeding complications in patients with atrial fibrillation: a systematic review. QJM 2007;100:599-607.

21. Palareti G, Cosmi B. Bleeding with anticoagulation therapy-who is at risk, and how best to identify such patients. Thromb Haemost 2009;102:268-78.

22. Pisters R, Lane DA, Nieuwlaat R, et al. A novel user-friendly score (HAS-BLED) to assess 1-year risk of major bleeding in patients with atrial fibrillation: the Euro Heart Survey. Chest 2010;138:1093-100.

23. Camm AJ, Kirchhof P, Lip GY, et al. European Heart Rhythm Association, European Association for Cardio-Thoracic Surgery. Guidelines for the management of atrial fibrillation: the Task Force for the Management of Atrial Fibrillation of the European Society of Cardiology (ESC). Eur Heart J 2010;31:2369-429.

24. Wilson W, Taubert KA, Gewitz M, et al. Prevention of infective endocarditis: guidelines from the American Heart Association: a guideline from the American Heart Association Rheumatic Fever, Endocarditis, and Kawasaki Disease Committee, Council on 
Cardiovascular Disease in the Young, and the Council on Clinical Cardiology, Council on Cardiovascular Surgery and Anesthesia, and the Quality of Care and Outcomes Research Interdisciplinary Working Group. Circulation 2007;116:1736-54.

25. Wahl MJ, Pinto A, Kilham J, et al. Dental surgery in anticoagulated patients-stop the interruption. Oral Surg Oral Med Oral Pathol Oral Radiol Endod 2015;119:136-57.

26. Herman WW, Konzelman JL, Sutley SH. Current perspectives dental patients receiving Coumarin anticoagulant therapy. J Am Dent Assoc 1997;128:327-35.

27. Little JW, Falace DA, Miller CS, et al. Bleeding disorder dental management of the medically compromised patients. 6 th edn. St Louis: Mosby, 2002:332-64.

28. Iwabuchi H, Imai Y, Asanami S, et al. Evaluation of postextraction bleeding incidence to compare patients receiving and not receiving warfarin therapy: across-sectional, multicenter, observational study. BMJ Open 2014;4:e005777.

29. Shikimori M. Clinical and hemostatic studies on dental extractions of patients undergoing oral anticoagulant therapy. Jpn Soc Oral Maxillofac Surg 1982;28:1629-42.

30. Halfpenny W, Fraser JS, Adlam DM. Comparison of 2 hemostatic agents for the prevention of postextraction hemorrhage in patients on anticoagulants. Oral Surg Oral Med Oral Pathol Oral Radiol Endod 2001;92:257-9.
31. Carter G, Goss A, Lloyd J, et al. Tranexamic acid mouthwash versus autologous fibrin glue in patients taking warfarin undergoing dental extractions: a randomized prospective clinical study. J Oral Maxillofac Surg 2003;61:1432-5.

32. Hong C, Napenas JJ, Brennan M, et al. Risk of postoperative bleeding after dental procedures in patients on warfarin: a retrospective study. Oral Surg Oral Med Oral Pathol Oral Radiol 2012;114:464-8.

33. Diener HC, Bogousslavsky J, Brass LM, et al. Aspirin and clopidogrel compared with clopidogrel alone after recent ischaemic stroke or transient ischemic attack in high-risk patients (MATCH): randomised, double-blind, placebo-controlled trial. Lancet 2004;364:331-7.

34. Toyoda K, Yasaka M, Iwade K, et al, Bleeding with Antithrombotic Therapy (BAT) Study Group. Dual antithrombotic therapy increases severe bleeding events in patients with stroke and cardiovascular disease: a prospective, multicenter, observational study. Stroke 2008;39:1740-5.

35. Holbrook AM, Pereira JA, Labiris R, et al. Systemic overview of warfarin and its drug and food interactions. Arch Intern Med 2005; $165: 1095-106$.

36. Clark NP, Delate T, Riggs CS, et al. Warfarin interactions with antibiotics in the ambulatory care setting. JAMA Intern Med 2014;174:409-16. 